
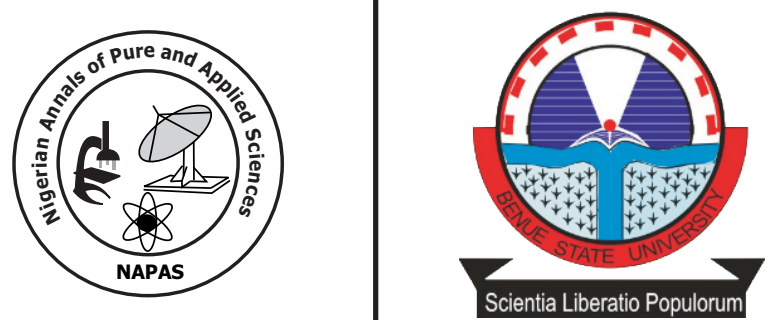

\title{
Kinetic and Thermodynamics of Adsorption of Heavy Metals from Spent Automobile Engine Oil onto Activated Carbon from Thevetia peruviana
}

\author{
${ }^{1}$ Leke, L.* , ${ }^{1}$ Dekaa, T.H. ${ }^{2}$ Olawuyi, S.0. and ${ }^{3}$ Nwosu, F.O.
}

1. Chemistry Department, Benue State University, Makurdi

2. Chemistry Department, Nigeria Defence Academy, Kaduna

3. Chemistry Department, University of Ilorin, Ilorin Kwara State

*Corresponding author:L.Leke@bsum.edu.ng

\section{Abstract}

The presence of heavy metals was analysed from oil samples employing the dry ashing method. The specific densities and viscosities of the spent and virgin AZ oil samples were determined and found to be $0.9230,0.9501$ and $70.27,73.27 \mathrm{cP}$ respectively. Kinetic and thermodynamic studies of the adsorption of lead $(\mathrm{Pb})$ and chromium $(\mathrm{Cr})$ from the spent oil was also investigated. The spent oil samples were digested and mixed with methyl isobutyl ketone (MIBK), agitated with activated carbon produced from Thevetia peruviana (bush milk) shells at various contact times of 2, 4, 5, 10, 15, 20, 30, 40, 50, 60, 90 and 120 minutes. Kinetic studies revealed that for lead $(\mathrm{Pb})$, the rate constants were found to be $0.044,0.060$ and $0.067 \mathrm{ppm} / \mathrm{min}$ at $27^{\circ} \mathrm{C}, 35^{\circ} \mathrm{C}$ and $45^{\circ} \mathrm{C}$, respectively, while higher values or rate constants of $0.126,0.127$ and $0,168 \mathrm{ppm} / \mathrm{min}$ were observed at $27{ }^{\circ} \mathrm{C}, 35^{\circ} \mathrm{C}$ and $45^{\circ} \mathrm{C}$, respectively, for chromium $(\mathrm{Cr})$. For the thermodynamic studies the Gibb's free energy $(\boldsymbol{\Delta G})$ values were; $-1.29,-1.61$ and $-1.82 \mathrm{KJmol}^{-1}$ at $27^{\circ} \mathrm{C}$, $35^{\circ} \mathrm{C}$ and $45^{\circ} \mathrm{C}$, respectively, indicating spontaneity. However, the Gibb's free energy $(\Delta \mathbf{G})$ for chromium showed $+0.050,-2.13$ and $-2.14 \mathrm{KJmol}^{-1}$ at $27{ }^{\circ} \mathrm{C}, 35^{\circ} \mathrm{C}$ and $45^{\circ} \mathrm{C}$, indicating non-spontaneity at $27^{\circ} \mathrm{C}$. The positive values of $\Delta \mathbf{S}$ for both metals with $\mathrm{Pb}\left(21-30 \mathrm{Jmol}^{-1}\right)$ and $\mathrm{Cr}\left(695-1867 \mathrm{Jmol}^{-1}\right)$ indicated that the metals were dissociatively adsorbed onto the adsorbent while for the $\mathbf{E}_{\mathrm{a}}$ values, $\mathrm{Cr}\left(8-61 \mathrm{KJmol}^{-1}\right)$ had higher than with $\mathrm{Pb}\left(6-35 \mathrm{KJmol}^{-1}\right)$ further explaining the non-spontaneity of the process for $\mathrm{Cr}$ at some reaction condition.

Key words: Activated carbon, heavy metals, kinetic, thermodynamic, AZ oil 


\section{Introduction}

Managing heavy metals in the environment is greatly of global concern. This is because they contaminate the abiotic factors of the environment like the soil, water and air, which in turn become toxic to the biotic factors (plants and animals) of the environment. Wastes from industries that carry out processes like electroplating, metal finishing, metallurgy, tannery operations, chemical processing, mine drainages, battery manufacturing, leachates from land fills, contaminated ground waters from hazardous waste sites, disposal of automobile oils and domestic waste are some of the main sources of these heavy metal in the environment (Meal et al, 1990; Reed et al, 1994; Leke et al, 2011; Bhat and Khan, 2011; Leke et al, 2012; and Safarzadeh et al, 2018). Since these heavy metals are toxic to life, the need for their safe handling, removal or recovery from their sources before disposal to the environment has attracted the attention of the research world. Heavy metals like lead $(\mathrm{Pb})$, chromium $(\mathrm{Cr})$, iron $(\mathrm{Fe})$, copper $(\mathrm{Cu})$, mercury $(\mathrm{Hg})$ cadmium (Cd) and so on cause diseases like brain damage, malfunctioning of the central nervous system (CNS), abnormal growth and development of plants and animals (Leke et al, 2012; Henry et al, 2015). Adsorption has been a process employed over the years for the removal and/or recovery of heavy metals from their sources especially from wastewater in trying to safe handle them in the environment (Gloaguen and Morvnor, 1997; Bulut and Baysal; 2005; Leke et $a l, 2012$ ). This process makes use of suitable substances (adsorbents) that hold onto them the heavy metals thereby separating them, from the matrix that contain them. Adsorbents employed for the adsorption of heavy metals include activated carbon, kaoline clay, zeolite and silica gel (Greankoplis, 1995; Mohammad and Nwaedozie, 2011; Leke et al, 2012).

Agricultural by-products have also found application as adsorbents for the removal of trace amounts of toxic heavy metals from the environment (Igwe et al, 2005). This could be due to economic reasons as agricultural byproducts can be acquired at relatively little cost. However, activated carbon has been more widely employed in adsorption over the years.

Spent automobile engine oil can be defined as any oil that has been refined from crude oil or synthetic oil, which has been used by automobiles and is considered spent as a result of use, and has become contaminated by physical or chemical impurities (USEPA, 1992).

Studies of the environment over the years have revealed contamination of water bodies, the soil and air by heavy metal through human activities (Igwe et al, 2005). Since automobiles are in common use by man, due to the demand for them, spent oils from automobiles have become a major source of heavy metals contaminants in the environment. Improper disposal of these oils to the environment cause them to contaminate the water and soil. These heavy metals from the oil get to the soil and to water, which find their way into the food chain by the plants taking them up either from the water or directly from the soil or air. Animals consume these toxic heavy metals subsequently and this is hazardous to health. This has the propensity to cause low life expectancy and high mortality rate of humans in third world countries like Nigeria. Thus proper treatment of spent automobile oils is required before disposal.

In view of this, adsorption onto activated carbon from plants appears to be the most interesting method on a large-scale application, simple technology and cost effectiveness (Kadirvelu and Namasivayam, 2003; Igwe and Abia, 2007; Mohammad and Nwaedozie, 2011; Leke et al, 2012). This implies that to fashion an effective model of adsorption, these factors would have to be studied to ascertain good performance. A study of the extent of adsorption of a substance with respect to time at various temperatures becomes important for kinetic and thermodynamic studies of adsorption of two heavy metals from the oils under investigation. This research was aimed at studying the trends of adsorption of two heavy metals $(\mathrm{Pb}$ and $\mathrm{Cr})$ from spent engine oils onto activated carbon prepared from Thevetia peruviana (bush milk) shells with respect to time and temperature.

\section{Materials and methods \\ Sample Collection}

The spent automobile engine oil samples were collected from various mechanic sites during the periodic change of engine oils from motor cars in Makurdi (North Central), Illorin (North Cental) and Ibadan (South West), all in Nigeria. The corresponding virgin oils were bought directly from the gas station. The oils investigated are,

- $\quad \mathrm{AZ}$ crown super high performance engine oil SAE 20W/50-API SG/CD

- Total quartz 5000 ultra-high performance multigrade engine oil. $20 \mathrm{~W} / 50-\mathrm{API}$ $\mathrm{SL} / \mathrm{CF}$

- $\quad$ Lubcon XV 50 premium quality motor oil. SAE 50API SF/CC. 
The activated carbon prepared from the nutshell of Thevetia peruviana commonly known as bush milk plant was supplied from Industrial Chemistry Laboratory, University of Ibadan.

\section{Sample Preparation and Preservation}

The oil samples were tightly corked in their plastic container and stored in the laboratory. The activated carbon was washed in $0.1 \mathrm{M} \mathrm{HCl}$, thoroughly rinsed in deionised water and dried in an oven at $105^{\circ} \mathrm{C}$ for about 1 hour. It was cooled and stored in desiccators.

\section{Apparatus and Reagents}

Apparatus and/or instruments used were common laboratory apparatus and instrument except otherwise mentioned in the experimental. Reagents used in the experiment include: $98.4 \%$ methyl pentane-2-one (MIBK), 99.6\% glacial acetic acid, 97\% sulphuric acid, $70 \%$ nitric acid, 70\% perchloride acid and 98\% sodium acetate. All these reagents were used as manufactured by BDH.

\section{Experimental \\ Determination of Specific Density and Viscosity}

Determination of specific density of the various oil samples was carried out using the method as reported by Murrell and Jenkini (1994). The specific density experiment was carried out at laboratory temperature measured to be $27{ }^{\circ} \mathrm{C}$. Kinematics viscosity measured in centipoise $(\mathrm{cP})$, is a measure of the resistance to flow of a substance under the influence of gravity. It is determined using the Ostwald viscometer as reported by Atkins and Paula (2002). Viscosity experiments were carried out and reported at a laboratory temperature also measured to be $27^{\circ} \mathrm{C}$.

\section{Determination of Heavy Metal Ions}

In the determination of heavy metals ions, the oil samples were first digested. The method for the determination of metal ions in the oils are the dry-ash and the wet digestion methods (Gorsuch, 1970). The dry ash methods of oil sample digestion was explored in the experimental of this research.

\section{Dry Ash Method}

This method of heavy metals determination from oil is as recommended by Milner et al (1952). About $2.5 \mathrm{~g}$ of the oil samples were treated with equal volume of concentrated sulphuric acid in a crucible thoroughly stirred and heated gradually on a thermostatic hot plate to dryness for about 3-5 hour. The crucible containing the dried oil sample subsequently transferred to a muffle furnace and ignited at $550{ }^{\circ} \mathrm{C}$ until all traces of carbon were removed. This was indicated by the absence of charcoal black colour. The ashing process in the muffle furnace at $550{ }^{\circ} \mathrm{C}$ took about 50-60 minutes. The crucible, containing the ash was then removed after cooling to about $200{ }^{\circ} \mathrm{C}$ and placed in a desiccators. The ash was then treated with $6 \mathrm{ml} \mathrm{HNO}_{3}$ in a $20 \mathrm{ml}$ volumetric flask and made up to mark with deionised water. The heavy metals present were determined using Atomic Absorption spectrophotometer.

\section{Kinetics Studies of Adsorption}

$29 \mathrm{ml}$ each was measured out of the $50 \%$ oil: MIBK solution prepared. About $0.2 \mathrm{~g}$ of the activated carbon was measured and mixed with each of the $20 \mathrm{ml}$ measured. This was shaken for different time durations of 2, 4, 5, 10, 15, 20, 30, 40, 60, 90 and 120 minutes, on a thermostated shaker. After each contact time specified, a container was removed from the shaker and configured for about 5 minutes. It was then decanted into a sample bottle leaving behind the activated carbon. The solutions analysis for determination of the metal ions present.

The $\mathrm{pH}$ of the samples was kept constant at 4.8 before shaking by introducing a $\mathrm{pH}$ buffer prepared by mixing $30 \mathrm{ml}$ of the $1 \mathrm{M}$ Acetic acid produced with $30 \mathrm{ml}$ of the $1 \mathrm{M}$ sodium acetate earlier prepared. The kinetic experiment was performed at $27^{\circ} \mathrm{C}, 35^{\circ} \mathrm{C}$ and $45^{\circ} \mathrm{C}$.

\section{Determination of Kinetic Parameters}

The kinetic rate constant for Lead $(\mathrm{Pb})$ and chromium (Cr) for the three (3) different temperatures were calculated using the pseudo second order equation expressed as (Low et al 2000, Ho and McKay, 1999):

$$
\mathrm{t} / \mathrm{Q}_{\mathrm{t}}=1 / \mathrm{k}+1 / \mathrm{C}_{\mathrm{e}} \cdot \mathrm{t}
$$

Where $t$ is contact time, $Q_{t}$ is concentration/quantity adsorbed at time $t, \mathrm{C}_{e}$ is Concentration/quantity adsorbed at equilibrium, $\mathrm{K}_{\mathrm{c}}$ is rate constant.

The equilibrium constant $\mathrm{K}_{\mathrm{c}}$ is also calculated using the formula reported by Panayotova (2001), Bekta and Kara (2001) and Komarneni (1985):

\section{$\mathbf{K}_{\mathbf{c}}={ }_{e e o} C C C-$}

Where $\mathrm{K}_{\mathrm{c}}$ is Equilibrium constant (nondimensional), $\mathrm{C}_{\mathrm{o}}$ is Initial concentration of $\mathrm{Pb}$ or $\mathrm{Cr}, \mathrm{C}_{\mathrm{e}}$ is Concentration of $\mathrm{Pb}$ or $\mathrm{Cr}$ equilibrium 


\section{Determination of Thermodynamics Parameters}

The thermodynamic parameters of the adsorption lead $(\mathrm{Pb})$ and chromium $(\mathrm{Cr})$ on the activated Carbon adsorbent were calculated using the following formulae (Okonjo et al, 2005).

$$
\begin{array}{rll}
\Delta \mathbf{G} & = & -\mathbf{R} \mathbf{T} \mathbf{I n} \mathbf{K c} \\
\Delta \mathbf{G} & = & \frac{2.303 R T_{1} T_{2}}{T_{1}-T_{2}} \log \frac{K_{C T 1}}{K_{C T 2}} \\
\mathbf{\Delta G} & = & \mathbf{\Delta} \mathbf{H}-\mathbf{T} \Delta \mathbf{S} \\
\mathbf{E a} & = & \frac{R T_{1} T_{2}}{T_{1}-T_{2}} \operatorname{In} \frac{k_{1}}{k_{2}}
\end{array}
$$

Where $\Delta \mathrm{G}$ is Gibb's free Energy $\left(\mathrm{Kjmol}^{-1}\right)$, $\Delta \mathrm{H}$ is Enthalpy $\left(\mathrm{Kjmol}^{-1}\right), \Delta \mathrm{S}$ is Entropy $\left(\mathrm{Kjmol}^{-}\right.$ $\left.{ }^{1}\right)$, $\mathrm{R}$ is Gas Constant ( $\mathrm{J}$ Mol. $\left.{ }^{-1}\right)$, $\mathrm{T}$ is Temperature ( $\mathrm{K}), \mathrm{Kc}$ is Equilibrium constant (a dimensional), $\mathrm{k}$ is Rate Constant

\section{Results and Discussion Specific Density and Viscosity of the Oils}

Table, shows variation of data of specific density as well as viscosity of automobile virgin and spent oils.

Table 1: Specific Densities and Viscosities of the virgin and their corresponding spent automobile oils.

\begin{tabular}{lcc}
\hline \multicolumn{1}{c}{ Oil Sample } & Specific Density & Viscosity (cP) \\
\hline Virgin Lubcon oil Performa (VLOP) & 0.9428 & 79.27 \\
Virgin Lubcon oil NATTA (VLOT) & 0.9408 & 76.77 \\
Spent Lubcon oil-Toyota (ULOT) & 0.9252 & 67.77 \\
Virgin Lubcon oil-Nissan (ULON) & 0.9322 & 64.27 \\
Virgin Total oil (VTO) & 0.9523 & 72.77 \\
Spent Total Oil-Toyota (UTOT) & 0.9269 & 66.77 \\
Virgin AZ Oil (VAZO) & 0.9501 & 73.27 \\
Spent AZ Oil Mercedes (UAZOM) & 0.9230 & 70.27 \\
\hline
\end{tabular}

The specific density for the virgin oils range $0.9408-0.9523$ while the spent oils are 0.9230 , $0.9252,0.9269$. 0.9322, for the UAZOM), (ULOT), (UTOT) and (ULON), respectively. It can be observed that the virgin oils are denser than their corresponding spent oils. However, the differences are quite small. This trend could be attributed to the fact that during combustion in an automobile engine, the oil in the engine is heated up through the various sections it passes. Consequently, some components of the oils are spent up. The oils are thus expected to be exhausted and become less dense as compared to their virgin ones. However, impurities from the various engine components, which these oils pass through, wear out and contaminate the oil. A similar trend has been reported by McKenzie (1981).

The results of the viscosity of the various oils as shown also in table 1 indicate that the virgin oils are more viscous as compared to their corresponding spent oils. Louis (2005) attributed low viscosity of oils to contamination of the oils by fuels and other impurities from the engines of automobiles. This adulteration accounts for the lowering of the viscosity of the oils after use in engines. For instance, the virgin Lubcon oil (VLO) has a viscosity of $79.27 \mathrm{cP}$ while that of spent Lubcon Oil-Toyota (ULOT) is $67.77 \mathrm{cP}$.

\section{Metal Content of the Oil Samples}

This method showed a general increase in the metal ion concentration in the spent oil as compared to their corresponding virgin oils as normally expected. The spent AZ oil (UAZOM) showed the most prominent increase in concentration of Lead $(\mathrm{Pb})$ and chromium $(\mathrm{Cr})$ relative to their virgin oils. McKenzie (1981) attributed the cause of contamination of oil by Lead $(\mathrm{Pb})$ as a result of furl and bearing wear while chromium as a result of piston-wear. These two metal ions were chosen for the kinetic and thermodynamic studies of the spent AZ oil (UAZOM).

The various data obtained for the kinetic studies of Lead $(\mathrm{Pb})$ and chromium $(\mathrm{Cr})$ at $27{ }^{\circ} \mathrm{C}$ (laboratory temperature), $35^{\circ} \mathrm{C}$ and $45^{\circ} \mathrm{C}$ were as shown in tables. 
Table 1: Kinetic Studies of the adsorption of Lead $(\mathrm{Pb})$ with respect to time at $27^{\circ} \mathrm{C}$.

\begin{tabular}{|c|c|c|c|c|c|c|}
\hline$t$ (mins) & $\mathbf{R}$ & $\mathrm{C}_{\mathrm{o}}(\mathrm{ppm})$ & $\mathrm{C}_{\mathrm{t}}(\mathrm{ppm})$ & $Q_{t}(p p m)$ & $\mathbf{t} / \mathbf{Q}_{\mathrm{t}}(\mathrm{min} / \mathrm{ppm})$ & $Q_{t}(\%)$ \\
\hline 0 & 1.014 & 15.598 & & - & - & - \\
\hline 2 & 1.011 & 15.598 & 15.552 & 0.046 & 43.48 & 0.29 \\
\hline 4 & 0.967 & 15.598 & 14.875 & 0.732 & 5.533 & 4.64 \\
\hline 5 & 0.943 & 15.598 & 14.506 & 1.092 & 4.58 & 7.00 \\
\hline 10 & 0.945 & 15.598 & 14.537 & 1.061 & 9.43 & 6.89 \\
\hline 15 & 0.036 & 15.598 & 14.398 & 1.200 & 12.50 & 7.69 \\
\hline 20 & - & 15.598 & - & - & - & - \\
\hline 30 & 0.939 & 15.598 & 14.444 & 1.154 & 26.00 & 7.40 \\
\hline 40 & 0.931 & 15.598 & 14.321 & 1.277 & 31.32 & 8.19 \\
\hline 50 & 0.935 & 15.598 & 14.383 & 1.215 & 41.15 & 7.79 \\
\hline 60 & 0.889 & 15.598 & 13.675 & 1.928 & 31.12 & 12.36 \\
\hline 90 & 0.862 & 15.598 & 13.260 & 2.338 & 38.49 & 14.99 \\
\hline 120 & 0.831 & 15.598 & 12.783 & 2.815 & 42.63 & 18.05 \\
\hline
\end{tabular}

Table 2: Kinetic Studies of the adsorption of Lead $(\mathrm{Pb})$ with respect to time at $35^{\circ} \mathrm{C}$.

\begin{tabular}{ccccccc}
\hline $\mathbf{t}$ (mins) & $\mathbf{R}$ & $\mathbf{C}_{\mathbf{o}} \mathbf{( p p m )}$ & $\mathbf{C}_{\mathbf{t}} \mathbf{( p p m )}$ & $\mathbf{Q}_{\mathbf{t}} \mathbf{( p p m )}$ & $\mathbf{t} / \mathbf{Q}_{\mathbf{t}} \mathbf{( \mathbf { m i n } / \mathbf { p p m } )}$ & $\mathbf{Q}_{\mathbf{t}} \mathbf{( \% )}$ \\
\hline 0 & 1.014 & 15.598 & & - & - & - \\
2 & 1.011 & 15.598 & 15.552 & 0.046 & 43.48 & 0.29 \\
4 & - & 15.598 & - & - & - & - \\
5 & 0.001 & 15.598 & 15.398 & 0.200 & 25.00 & 1.28 \\
10 & 0.936 & 15.598 & 14.398 & 1.200 & 12.00 & 7.69 \\
15 & 0.938 & 15.598 & 14.429 & 1.169 & 12.83 & 7.49 \\
20 & 0.919 & 15.598 & 14.137 & -1.461 & 13.700 & 9.37 \\
30 & - & 15.598 & - & - & - & - \\
40 & 0.903 & 15.598 & 13.890 & 1.708 & 23.40 & 10.95 \\
50 & 0.877 & 15.598 & 13.491 & 2.107 & 23.73 & 13.51 \\
60 & 0.867 & 15.598 & 13.337 & 2.261 & 26.54 & 14.50 \\
90 & 0.865 & 15.598 & 13.306 & 2.209 & 39.27 & 14.69 \\
120 & 0.799 & 15.598 & 12.291 & 3.307 & 36.29 & 21.20 \\
\hline
\end{tabular}

Table 3: Kinetic Studies of the adsorption of Lead $(\mathrm{Pb})$ with respect to time at $45^{\circ} \mathrm{C}$.

\begin{tabular}{ccccccc}
\hline $\mathbf{t}(\mathbf{m i 1} \mathbf{n s})$ & $\mathbf{R}$ & $\mathbf{C}_{\mathbf{o}} \mathbf{( \mathbf { p p m } )}$ & $\mathbf{C}_{\mathbf{t}} \mathbf{( \mathbf { p p m } )}$ & $\mathbf{Q}_{\mathbf{t}} \mathbf{( \mathbf { p p m } )}$ & $\left.\mathbf{t} / \mathbf{Q}_{\mathbf{t}} \mathbf{( \mathbf { m i n }} / \mathbf{p p m}\right)$ & $\mathbf{Q}_{\mathbf{t}} \mathbf{( \% )}$ \\
\hline 0 & 1.014 & 15.598 & - & - & - & - \\
2 & 1.004 & 15.598 & 15.444 & 0.154 & 12.99 & 0.99 \\
4 & 1.003 & 15.598 & 15.429 & 0.431 & 11.60 & 2.07 \\
5 & 0.986 & 15.598 & 15.167 & 0.169 & 23.67 & 1.08 \\
10 & 0.993 & 15.598 & 15.279 & 0.323 & 30.96 & 2.07 \\
15 & 0.997 & 15.598 & 15.029 & 0.564 & 26.60 & 3.65 \\
20 & 0.950 & 15.598 & 14.613 & 0.985 & 20.30 & 6.31 \\
30 & 0.940 & 15.598 & 14.460 & 1.138 & 26.36 & - \\
40 & - & 15.598 & - & - & - & - \\
50 & 0.869 & 15.598 & 13.367 & 2.234 & 22.41 & 14.30 \\
60 & 0.863 & 15.598 & 13.275 & 2.323 & 25.41 & 14.89 \\
90 & 0.847 & 15.598 & 13.025 & 2.573 & 34.98 & 16.47 \\
120 & 0.795 & 15.598 & 12.229 & 3.369 & 35.62 & 21.60 \\
\hline
\end{tabular}


Table 4: Kinetic Studies of the adsorption of Chromium $(\mathrm{Cr})$ with respect to time at $27^{\circ} \mathrm{C}$

\begin{tabular}{ccccccc}
\hline $\mathbf{t}$ (mi1ns) & $\mathbf{R}$ & $\mathbf{C}_{\mathbf{o}} \mathbf{( p p m )}$ & $\mathbf{C}_{\mathbf{t}} \mathbf{( p p m )}$ & $\mathbf{Q}_{\mathbf{t}} \mathbf{( p p m )}$ & $\left.\mathbf{t} / \mathbf{Q}_{\mathbf{t}} \mathbf{( m i n} \mathbf{p p m}\right)$ & $\mathbf{Q}_{\mathbf{t}} \mathbf{( \% )}$ \\
\hline 0 & 0.531 & 8.168 & - & - & - & - \\
2 & 0.501 & 8.168 & 7.707 & 0.461 & 4.34 & 5.64 \\
4 & 0.493 & 8.168 & 7.584 & 0.584 & 6.85 & 7.17 \\
5 & 0.493 & 8.168 & 7.338 & 0.830 & 6.02 & 10.16 \\
10 & 0.472 & 8.168 & 7.261 & 1.907 & 5.24 & 11.10 \\
15 & 0.466 & 8.168 & 7.168 & 1.000 & 15.00 & 12.24 \\
20 & 0.461 & 8.168 & 7.092 & 1.076 & 18.59 & 13.17 \\
30 & 0.433 & 8.168 & 6.661 & 1.507 & 19.91 & 18.45 \\
40 & 0.396 & 8.168 & 6.092 & 2.076 & 19.27 & 25.42 \\
50 & - & 8.168 & - & - & - & - \\
60 & 0.3562 & 8.168 & 5.483 & 2.685 & 22.35 & 32.87 \\
90 & 0.390 & 8.168 & 5.999 & 2.169 & 41.49 & 25.55 \\
120 & 0.386 & 8.168 & 5.938 & 2.230 & 53.81 & 27.30 \\
\hline
\end{tabular}

Table 5: Data Kinetic Studies of Chromium $(\mathrm{Cr})$ at $35^{\circ} \mathrm{C}$.

\begin{tabular}{ccccccc}
\hline $\mathbf{t}(\mathbf{m i 1} \mathbf{n s})$ & $\mathbf{R}$ & $\mathbf{C}_{\mathbf{0}} \mathbf{( p p m )}$ & $\mathbf{C}_{\mathbf{t}}(\mathbf{p p m})$ & $\mathbf{Q}_{\mathbf{t}}(\mathbf{p p m})$ & $\left.\mathbf{t} / \mathbf{Q}_{\mathbf{t}} \mathbf{( \mathbf { m i n }} / \mathbf{p p m}\right)$ & $\mathbf{Q}_{\mathbf{t}} \mathbf{( \% )}$ \\
\hline 0 & 0.531 & 8.168 & - & - & - & - \\
2 & 0.501 & 8.168 & 7.707 & 0.461 & 4.34 & 5.56 \\
4 & 0.498 & 8.168 & 7.661 & 0.507 & 7.89 & 6.21 \\
5 & 0.494 & 8.168 & 7.599 & 0.569 & 8.79 & 6.97 \\
10 & 0.493 & 8.168 & 7.584 & 0.854 & 17.12 & 7.15 \\
15 & 0.486 & 8.168 & 7.476 & 0.692 & 21.68 & 8.47 \\
20 & 0.483 & 8.168 & 7.430 & 0.738 & 27.10 & 9.04 \\
30 & 0.4614 & 8.168 & 7.097 & 0.071 & 28.00 & 13.11 \\
40 & - & 8.168 & - & - & - & - \\
50 & 0.411 & 8.168 & 6.415 & 1.753 & 28.52 & 21.46 \\
60 & 0.417 & 8.168 & 6.417 & 1.751 & 36.27 & 21.44 \\
90 & 0.398 & 8.168 & 6.122 & 2.046 & 43.99 & 25.05 \\
120 & 0.371 & 8.168 & 5.707 & 2.461 & 48.76 & 30.13 \\
\hline
\end{tabular}

Table 6: Data Kinetic Studies of Chromium $(\mathrm{Cr})$ at $45{ }^{\circ} \mathrm{C}$.

\begin{tabular}{ccccccc}
\hline $\mathbf{t}$ (mi1ns) & $\mathbf{R}$ & $\mathbf{C}_{\mathbf{o}} \mathbf{( p p m )}$ & $\mathbf{C}_{\mathbf{t}} \mathbf{( p p m )}$ & $\mathbf{Q}_{\mathbf{t}} \mathbf{( p p m )}$ & $\left.\mathbf{t} / \mathbf{Q}_{\mathbf{t}} \mathbf{( m i n} / \mathbf{p p m}\right)$ & $\mathbf{Q}_{\mathbf{t}} \mathbf{( \% )}$ \\
\hline 0 & 0.531 & 8.168 & - & - & - & - \\
2 & 0.503 & 8.168 & 7.737 & 0.431 & 4.64 & 5.28 \\
4 & 0.501 & 8.168 & 7.707 & 0.461 & 8.68 & 5.64 \\
5 & 0.488 & 8.168 & 7.507 & 0.661 & 7.56 & 8.09 \\
10 & 0.476 & 8.168 & 7.322 & 0.846 & 11.82 & 10.36 \\
15 & 0.441 & 8.168 & 6.784 & 1.384 & 10.84 & 16.94 \\
20 & 0.432 & 8.168 & 6.645 & 1.523 & 13.13 & 18.65 \\
30 & 0.429 & 8.168 & 6.699 & 1.469 & 20.42 & 17.98 \\
40 & 0.413 & 8.168 & 6.353 & 1.815 & 22.04 & 22.22 \\
50 & 0.400 & 8.168 & 6.153 & 2.015 & 24.81 & 24.67 \\
60 & 0.398 & 8.168 & 6.122 & 2.046 & 29.33 & 25.25 \\
90 & 0.314 & 8.168 & 4.830 & 3.338 & 27.00 & 40.87 \\
120 & 0.312 & 8.168 & 4.800 & 3.368 & 35.63 & 41.23 \\
\hline
\end{tabular}

Where $t$ is time, $R$ is Instrument Reading, $\mathrm{C}_{\mathrm{o}}$ is Initial concentration at $\mathrm{t}=0, \mathrm{C}_{\mathrm{t}}$ is Concentration at $\mathrm{t}=\mathrm{t}, \mathrm{Q}_{\mathrm{t}}$ is Amount Adsorbed at time, $\mathrm{t}$

From the data of the kinetic studies of the two (2) metals here considered, shown in Table $2-7$, the initial concentration of lead $(\mathrm{Pb})$ and chromium $(\mathrm{Cr})$ were found to be $15.59 \mathrm{ppm}$ and $8.16 \mathrm{ppm}$ respectively in the spent oil under investigation. The results of agitation with the adsorbent at various contacts time at three different temperatures $\left(27^{\circ} \mathrm{C}\right.$, $35^{\circ} \mathrm{C}$ and $45^{\circ} \mathrm{C}$ ) reveals the following:

\section{Effect of Temperature on Adsorption}

The amount of lead $(\mathrm{Pb})$ and chromium $(\mathrm{Cr})$ adsorbed was observed to increase with increase in temperature. For instance after 120 minutes, the amount of lead $(\mathrm{Pb})$ adsorbed increased from 2.815 ppm at $27^{\circ} \mathrm{C}$ to $3.307 \mathrm{ppm}$ at $35^{\circ} \mathrm{C}$ and to $3.369 \mathrm{ppm}$ at $45{ }^{\circ} \mathrm{C}$. This represents an increase in percentage adsorption from $18.05 \%$ to $21.20 \%$ and to $21.60 \%$ respectively. Similarly, after 120 minutes, the 
amount of chromium $(\mathrm{Cr})$ adsorbed increase from $2.230 \mathrm{ppm}$ at $27^{\circ} \mathrm{C}$ to $2.461 \mathrm{ppm}$ at $35^{\circ} \mathrm{C}$ and to $3.368 \mathrm{ppm}$ at $45^{\circ} \mathrm{C}$ representing $27.30 \%$ to $30.13 \%$ and to $41.25 \%$ respectively. Raji and Aniradhan, (1997) have attributed such increase adsorption of metal ions with increasing temperature to be due to desolvation of sorbing species and/or changes in pore sizes of the adsorbent. This also indicates that the adsorption process is endothermic in nature. Al-Ashah and Duvrijak (1998) have also reported the rate of adsorption as being temperature dependent.

\section{Effect of Contact time on Adsorption}

Adsorption was generally observed to increase with contact time of the oil with the adsorbent both for lead $(\mathrm{Pb})$ and chromium $(\mathrm{Cr})$ at the three (3) temperatures considered as shown by the results in the tables. The effect of the change of the concentration as a result of varying contact time was the basis on which the Kinetics of this process was studied.

\section{Kinetic Parameters}

Plotting $\mathrm{t} / \mathrm{Q}_{\mathrm{t}}$ against $\mathrm{t}$ for the data in tables 2 to 7 , for Lead $(\mathrm{Pb})$ and chromium $(\mathrm{Cr})$ at $27^{\circ} \mathrm{C}, 35$ ${ }^{\circ} \mathrm{C}$ and $45^{\circ} \mathrm{C}$, a straight line graph is obtained with $1 / \mathrm{k}$ as the intercept on the $\mathrm{t} / \mathrm{Q}_{\mathrm{t}}$ axis and $1 / \mathrm{C}_{\mathrm{e}}$ as the slope. From these graphs, the rate constant $\mathrm{k}$ for lead $(\mathrm{Pb})$ and chromium $(\mathrm{Cr})$ at each temperature was calculated. This kinetic parameters obtained from the plots are as shown in the tables 7 and 8 below:

Table 7: Rate and equilibrium constants calculated for lead $(\mathrm{Pb})$ adsorption.

\begin{tabular}{ccc}
\hline Temperature T(K) & Rate Constant k (ppm/min) & Equilibrium Constant (Kc) \\
\hline 318 & 0.067 & 1.992 \\
308 & 0.060 & 1.876 \\
300 & 0.045 & 1.675 \\
\hline
\end{tabular}

Table 7: Rate and equilibrium constants calculated for chromium (Cr) adsorption.

\begin{tabular}{ccc}
\hline Temperature T(K) & Rate Constant k (ppm/min) & Equilibrium Constant $\left(\mathbf{K}_{\mathbf{c}}\right)$ \\
\hline 318 & 0.168 & 2.244 \\
308 & 0.127 & 2.091 \\
300 & 0.126 & 0.981 \\
\hline
\end{tabular}

From the kinetic parameters for the $\mathrm{Pb}$ and $\mathrm{Cr}$ (Table 7 and 8), it is observed generally that the higher the temperature, the higher the rate constant $\mathbf{k}$ of the adsorption process and the higher the equilibrium constant $\mathbf{K}_{\mathbf{c}}$. Atkins and Paula (2002) presented similar trend of results for reactions with similar conditions.

The thermodynamic parameters for the adsorption of the Lead $(\mathrm{Pb})$ and chromium $(\mathrm{Cr})$ on the activated carbon are shown in the tables below;

Table 8: Thermodynamic Parameters for Lead $(\mathrm{Pb})$ adsorption.

\begin{tabular}{|c|c|c|c|c|}
\hline Temperature (K) & $\begin{array}{l}\text { Gibb's Free Energy } \\
\Delta \mathrm{G}\left(\mathrm{KJmol}^{-1}\right)\end{array}$ & $\begin{array}{l}\text { Enthalpy } \Delta \mathbf{H} \\
\left(\mathrm{KJmol}^{-1}\right)\end{array}$ & $\begin{array}{l}\text { Entropy } \Delta S \\
\left(\mathrm{Jmol}^{-1}\right)\end{array}$ & $\begin{array}{l}\text { Activation Energy } \mathrm{E}_{\mathrm{a}} \\
\left(\mathrm{KJmol}^{-1}\right)\end{array}$ \\
\hline 318 & -1.82 & 4.86 & 21.0 & 6.54 \\
\hline 308 & -161 & 10.9 & 40.6 & 34.34 \\
\hline 300 & -1.29 & 7.6 & 29.7 & 24.74 \\
\hline
\end{tabular}

Table 1: Thermodynamic Parameters for Chromium (Cr) adsorption.

\begin{tabular}{lllll}
\hline Temperature (K) & $\begin{array}{l}\text { Gibb's Free Energy } \\
\boldsymbol{\Delta G}\left(\mathbf{K J m o l}^{\mathbf{- 1}}\right)\end{array}$ & Enthalpy $\mathbf{\Delta H}\left(\mathbf{K J m o l}^{-\mathbf{1}}\right)$ & $\begin{array}{l}\text { Entropy } \boldsymbol{\Delta S} \\
\left(\mathbf{J m o l}^{\mathbf{- 1}}\right)\end{array}$ & $\begin{array}{l}\text { Activation Energy } \\
\mathbf{E a}\left(\mathbf{K J m o l}^{\mathbf{- 1}}\right)\end{array}$ \\
\hline 318 & -2.14 & 218.8 & 695.0 & 55.5 \\
308 & -2.13 & 1022.4 & 3325.0 & 8.2 \\
300 & +0.05 & 562.3 & 1867.0 & 60.9 \\
\hline
\end{tabular}


From the thermodynamic parameters given in the Tables 9 and 10 above, the values of $\Delta G^{0}<0$ implies spontaneity of the adsorption process. While the positive values of $\Delta \mathrm{G}$ at $27^{\circ} \mathrm{C}$ for Chromium indicates non-spontaneity of the process at the temperature.

The positive values of $\Delta \mathbf{H}^{\mathbf{0}}$ indicates an increase randomness at the solid/solution interface during the adsorption of the metal ions on the activated carbon implying an affinity of the activated carbon for the Lead $(\mathrm{Pb})$ ions and chromium $(\mathrm{Cr})$ ions under consideration. The $\Delta \mathrm{H}$ values of $4.86 \mathrm{KJ} / \mathrm{mol}, 10.90 \mathrm{KJ} / \mathrm{mol}$ and $7.60 \mathrm{KJ} / \mathrm{mol}$ at $45^{\circ} \mathrm{C}, 35^{\circ} \mathrm{C}$ and $27^{\circ} \mathrm{C}$ respectively for lead $(\mathrm{Pb})$ indicates physisorption processes while for chromium, $\Delta \mathrm{H}$ values of $218.83 \mathrm{KJ} / \mathrm{mol}$, $1022.4 \mathrm{KJ} / \mathrm{mol}$ and $562.3 \mathrm{KJ} / \mathrm{mol}$ at $45^{\circ} \mathrm{C}, 35^{\circ} \mathrm{C}$ and $27^{\circ} \mathrm{C}$ respectively indicates chemisorption processes (Atkins and Paula, 2002). This also suggests that there were some structural changes at the adsorbent - adsorbate interface for chromium (Ajmal et al 2003). The positive values of $\Delta \mathrm{S}$ for both the $\mathrm{Pb}$ and $\mathrm{Cr}$ metals are indicative of a dissociative adsorption process. While the comparatively higher values of $\Delta \mathrm{S}$ for the $\mathrm{Cr}$ are an indicator for the $\mathrm{Cr}$ as being more dissociatively adsorbed.

Activation energy $\mathbf{E}_{\mathrm{a}}$ being an indicator of the energy barrier to be overcome for the adsorption process to take place, shows that the process was basically feasible with values ranging from $6-61 \mathrm{kJmol}^{-1}$ and could indicate transition from a physisorption to a chemisorption process.

\section{Conclusion}

Results from this research showed that the adsorption of lead $(\mathrm{Pb})$ and chromium $(\mathrm{Cr})$ ions from spent AZ Oil (UAZO) onto activated carbon from Thevetia peruciana is affected by temperature and contact time. Thus, the higher the temperature, the higher the rate of adsorption, also the longer the contact time, the higher the rate of adsorption. The adsorption process followed a pseudo second order model from kinetic studies. The processes for lead $(\mathrm{Pb})$ were physisorption while those for chromium (Cr) were chemisorption. The adsorption processes were all spontaneous with negative values of Gibb's free energy $(\boldsymbol{\Delta G})$ at the three temperatures for lead $(\mathrm{Pb})$ and chromium $(\mathrm{Cr})$ except at temperature, $27^{\circ} \mathrm{C}$ (Laboratory temp) for chromium (Cr) where $\mathbf{\Delta} \mathbf{G}$ was positive indicating a non-spontaneous process. The metals were also dissociatively adsorbed onto the adsorbent in the processes as demonstrated by their +ve $\boldsymbol{\Delta} \mathbf{S}$ values with their $\mathbf{E}_{\mathrm{a}}$ within the same range of $6-35 \mathrm{kJmol}^{-1}$ for the $\mathrm{Pb}$ while $\mathrm{Cr}$ had $8-61 \mathrm{~kJ} \mathrm{~mol}^{-1}$

\section{Acknowledgement}

Financial Sponsorship and supervisory roles of Chief Joe T Leke and Dr K O Adebowale respectively, are graciously acknowledged.

\section{References}

Ajmal Ajmal M, Rao R.A.K. Amwar S, Ahmed J, Ahmad R, 2003. Adsorption Studies on Rice Husk: Removal and Recovery of Cd (III) from Waste Water. Bio-Resources Technol $86147-149$.

Al-Asheh S, Duvijak Z, 1998. Binary metal sorption by pine bark: Study of equilibrium and mechanisms. Separation Science and Technilogy 33 (9)1303-1329.

Atkins P.W. and Paula S. 2002. Physical Chemistry, Oxford Press, Great Britain. (Seventh Edition).

Bekta N and Kera S, 2004. Removal of Lead from aqueous solution by natural Clinoptilolite: Equilibrium and Kinetic Studies. Separation and Purification Technology 39 189-200

Bhat, U. N. and Khan, A. B. (2011). Heavy metals: An ambiguous category of inorganic contaminants, nutrients and toxins. Res. $J$. Env. Sc. 5(8): 682-690

Bullut $\mathrm{Y}$ and Baysal Z, 2006. Removal of $\mathrm{Pb}$ (III) from waste water using wheat brain. Journal of Environment Management 78. 107-113.

Gloaguen V. and Morvan H., 1997. Removal of heavy metal ion from aqueous solution by modified barks. Journal of Environmental Science Health A32 (4) 901-912.

Greankoplis C.j. 1995. Transport Processes for Unit Operations, Simon and Schuster Asia Ltd. Singapore.

Henry, H., Naujokas, M. F., Attanayake, C., Basta, N. T., Cheng, Z., Hettiarachchi, G. M., Maddaloni, M., Schadt, C. and Scheckel, K. G. (2015). Bioavailability-Based In Situ Remediation to meet future Lead $(\mathrm{Pb})$ Standards in Urban Soils and Gardens. Environ. Sci. Technol. 49: 8948-8958

HO, Y.S. and Mckay G, 1999. Pseudo Sound order model for sorption and processes. Process Biochem. 34, 451-465.

Igwe, J.C. and Abia, A.A. (2007). Equilibrium Sorption isotherm studies of $\mathrm{Cd}(\mathrm{II}), \mathrm{Pb}$ (II) and $\mathrm{Zn}(\mathrm{II})$ ions detoxification from wastewater using unmodified and EDTAModified maize husks. Electronic Journal of Biotechnology 10(4): 537-548.

Igwe J.C., Nwokennaya E.C., Abia A.A. 2005. The role of $\mathrm{pH}$ in heavy metal detoxification by bio-sorption from aqueous solutions 
containing chelating agents. African Journal of Biotech. 4(10) 1109-1112.

Kadirvelu K. and Namasivayam C. 2003. Activated Carbon from Coconut Coir pith as metal adsorbent: Adsorbent of Cd (II) from aqueous solution. Advance Environment Research 1471-478.

Komarneni S. 1985. Heavy metals removal from aqueous solution by tolermorites and Zeolites. Nuclear Chemistry Waste Management 5 247-250.

Leke, L., Aboi, J., Dekaa H.T., Ikyenge B. A., Ande, S., Okoronkwo M. U. (2012). Adsorption Kinetics of $\mathrm{Pb}$ (II) and $\mathrm{Zn}$ (II) ions unto Carbonized Groundnut Shells and Maize Cobs. European Journal of Scientific Research.84(3) pp.388-397

Leke Luter, Akaahan Terngu J. and Simon Attah (2011). Heavy metals in soils of auto mechanic shops and refuse dumpsites in Makurdi Nigeria. J. Appl. Sci. Environ. Manage. 15(1):207-210.

Louis C.E. 2005. Fuel dilution of oil www.louis.com Louis C. Eitzen Co. Last revised: 11/04/2005.

Low K.S., Lee C.K., and Lieu S.C. 2000. Sorption at Cadmium and Lead from aqueous solutions by spent grain. Process Bichem 36, 59-64.

McKenzie, T. 1981. Atomic Adsorption Spectrophotometry for Analysis of wear metals in oil samples. Varian Techntron Pty Ltd. Mulgrau, Victoria, Australia.

Mohammad, M.N. and Nwaedozie, J.M. (2011).
Application of Marine Biomass for the removal of metals from industrial wastewater. Greener Journal of Physical Sciences 1(1): 001-010.

Meal B.G., Lawrence E.B., Wendt J.L. 1990. Alkali metal partitioning in ash from pulverized coal combustion. Combustion Science Techn. 74, 211-214.

Okonjo K.O., Demihin A.A., Babalola J.O., Bankole T.O., Obi-Egbedi N.O., and Iweibo I. 2005. Fundamental Physical chemistry, Ibadan University Press.

Panayotova M.I. 2001. Kinetics and Thermodynamics of Copper ions removal from waste water by use of Zedilic. Waste Management, 21, 671-676.

Raji C. And Anirudhan T.S., 1997. Kinetics of Pb (II) adsorption by polyacrylamide grafted Sawdust. Ind Journal of Chemical Technol. 4, 157-162.

Reed B.F. Arunnachalam S., Thomas B. 1994. Removal of lead and cadmium from aqueous waste strems using granular activated carbon (GAC) columns. Environment Programme 13 60-65.

Safarzadeh, S., Kasmaei, L.S. and Abadi, Z. A. (2018). Effect of organic substances on iron-release kinetics in a calcareous soil after basil harvesting. J. Serb. Chem. Soc. 83 (7-8) 941-952

U.S. Environmental Protection Agency (USEPA), 1992. Hazardous Waste Management System Identification and Listing standards. Federal regulations 57 (176) 41566-41526. 